\title{
Behavioural responses, traumatic injuries and live weight losses in ostrich (Struthio camelus) chicks transported by road during hot-dry conditions
}

\author{
Ndazo Salka Minka' and Joseph Olusegun Ayo ${ }^{2}$ \\ ${ }^{1}$ College of Agriculture and Animal Science, Division of Agricultural Colleges, Ahmadu Bello University, Mando - \\ Kaduna, Nigeria, ${ }^{2}$ Department of Physiology and Pharmacology, Faculty of Veterinary Medicine, Ahmadu Bello \\ University, Zaria, Nigeria
}

\begin{abstract}
The aim of this study was to evaluate the effect of six-hour road transportation on behavioural activities, live weight and traumatic injuries of 40 (20 males and 20 females) ostrich chicks age 3.5 months. The average weight of the birds was $27.7 \mathrm{~kg}$. Four separate journeys were conducted and each vehicle was loaded with 10 ostriches. The behavioural events, environmental data, live weights and traumatic injuries were recorded before, during and after transportation. The result showed that the most stressful behaviours exhibited by the chicks during transportation were hyperventilation (66.7 $\pm 21.2 \%)$, wing fluffing ( $65 \pm 12.0 \%)$, and prolonged standing $(60 \pm 15.3 \%)$. The most frequent behaviours per hour of the journey were beak opening ( $5.9 \pm 1.8$ bouts), elimination ( $5.3 \pm 2.3$ bouts) and pecking (5.6 \pm 2.8 bouts). The chicks spent $27.0 \pm 11.8,18.2 \pm 1.0$, and $17.5 \pm 0.1$ min per hour of the journey, standing, restless and lying down, respectively. $15.0 \pm 2.3 \%$ of the chicks sustained mild injuries during handling and loading. The birds lost $6.5 \pm 1.4 \%$ of their live weight after transportation. The relationships between the journey period, temperature humidity index (THI) and stressful behaviours of wing fluffing, pecking, hyperventilation (beak opening) and lying down recorded during the transportation was positive and significant $(P<0.01)$, while behaviours of standing, elimination and restlessness were negatively and significantly $(P<0.01)$ correlated. Student's t-test and Pearson's correlation test were employed in the statistical analysis. The results suggest that $\mathrm{THI}$ of $33-40^{\circ} \mathrm{C}$ constitutes moderate risk, while that of $47^{\circ} \mathrm{C}$ and above may result in severe stressful behaviours, and this may be considered as recommended ranges and limits of thermal load values in transported chicks. In conclusion, six hours road transportation during hot-dry conditions and the introduction of ostrich chicks into a new environment post-transportation induce behavioural stress.
\end{abstract}

Keywords: behaviour, ostrich chick, road transportation, stress 


\section{Zusammenfassung}

\section{Verhaltensänderungen, traumatische Belastungen und Gewichtsreduzierung von Straußenküken (Struthio camelus) durch den Transport unter heiß-trockenen Umweltbedingungen}

Ziel der Untersuchung war es, die Auswirkungen eines sechsstündigen Tiertransports auf das Verhaltens, das Gewicht und die traumatische Belastungen von 40 Straußenküken (je 20 männlich und weiblich) im Alter von 3,5 Monaten und mit einem durchschnittlichen Gewicht von 27,7 Kg zu beurteilen. Vier Fahrten mit je 10 Straußen wurden durchgeführt. Das Verhalten, die Umweltbedingungen, das Gewicht und die traumatischen Belastungen wurden vor, während und nach der Fahrt erfasst. Die Küken zeigten während der Fahrt folgende gravierende Stressreaktionen: Hyperventilation (66,7 $\pm 21,2 \%)$, Aufplustern $(65 \pm 12,0 \%)$ und langanhaltendes Stehen (60 $\pm 15,3 \%)$. Die häufigsten Verhaltensweisen pro Fahrtstunde waren: Schnabel

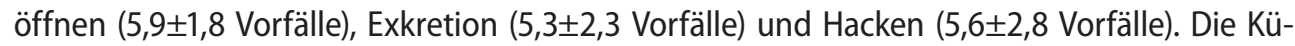
ken verbrachten jeweils $27,0 \pm 11,8,18,2 \pm 1,0$, und 17,5 $\pm 0,1$ min pro Stunde der Fahrt stehend, unruhig und liegend. 15,0 2 2,3\% der Küken erlitten leichte Verletzungen. Die Vögel hatten nach der Fahrt 6,5 $\pm 1,4 \%$ ihres Lebendgewichts verloren. Die Beziehungen zwischen Fahrtzeit, Temperatur-Luftfeuchtigkeits-Index (THI) und den Stressreaktionen Aufplustern, Hacken, Hyperventilation und Liegen korrelierten positiv und signifikant $(P<0,01)$, während die Verhaltensweisen Stehen, Exkretion und Unruhe negativ und signifikant $(P<0,01)$ korrelierten (Student-t-Verteilung, Korrelationskoeffizient). Dabei zeigte sich, dass bei einem THI von $33-40^{\circ} \mathrm{C}$ ein geringeres Risiko für Stressreaktionen besteht, während es bei einem THI von $47^{\circ} \mathrm{C}$ und mehr zu schwerwiegenden Stressreaktionen kommen kann. Damit sind auch die empfehlenswerten Temperaturbereiche und -grenzen für den Transport von Straußenküken definiert.

Schlüsselwörter: Verhalten, Straußenküken, Tiertransport, Stress

\section{Introduction}

The increasing interest in production of the ostrich (Struthio camelus) due to its high-quality meat and products, tourist attraction in zoos and re-stocking of game reserves has resulted in the transportation of the bird far away from were they are produced (Cooper \& Horbanczuk 2000, Minka 2003, Minka \& Ayo 2008). Transportation of ostriches is very stressful and poses a great risk to both man and the bird itself. This is because the ostrich is bipedal, with twotoed feet and a height of about $3 \mathrm{~m}$. During transportation, ostriches suffer from postural instability due to their high centre of gravity, resulting in severe traumatic injuries and high mortality (Foggin 1992, Wotton \& Hewitt 1999, Minka \& Ayo 2008).

Generally there are few recommendations relating solely to the welfare of ostriches during road transportation (Maff 1998, Piccione et al. 2005, Minka \& Ayo 2007c, 2008). Besides, each age group requires different transportation conditions including vehicle design. The duration and conditions of the journey may affect the welfare of the birds. Ostrich chicks are mostly purchased and transported in Nigeria from the Northern Guinea Savannah zone, where they are predominantly reared, to new farms, markets and zoos and game reserves in the Southern Guinea Savannah zone (Minka \& Ayo 2008). This road transportation covers distances ranging 
from 200 to over $1000 \mathrm{~km}$ and the use of vehicles specifically not meant for transportation of ostriches, and with little consideration for the ostrich welfare (Minka \& Ayo 2007c, 2008). Lack of adequate welfare measures during transportation of ostriches has generated sharp criticisms from human right and animal welfare activists all over the world (Brown 1997, Minka \& Ayo 2008).

It has been established that changes in behavioural events of animals, including birds are reliable index of stress and are often used in the development of management strategies, aimed at increasing productivity. They are important for on-the-spot evaluation of the health status and adaptability of animals to various stress factors, including transportation stress (Warriss et al. 1993, Ayo et al. 2002, Minka \& Ayo 2007a, b, 2008). Very often behavioural changes are the main signs of distress and the first signs of disease in animals (Ayo et al. 2002). There is a great need for further investigations of the vehicle design, behaviour and health status of transported ostrich chicks in order to obtain optimum on-board conditions for transportation of ostriches by road, especially during the hot-dry season, known to be thermally stressful to birds (Minka \& Ayo 2007c, 2010). Results of such studies may be of value to the animal welfarist, zoologists and the entire ostrich industry, in improving ostrich welfare during transportation.

The aim of the present study was to evaluate the effects of 6 hours of road transportation during the hot-dry conditions, and thermal load on behavioural events, traumatic injuries and live weight losses of ostrich chicks.

\section{Materials and methods}

\section{Thermal environmental data}

The ambient temperature (AT) and relative humidity (RH) were recorded at the sites of the study for seven days before and after transportation at 07:00, 14:00 and 18:00. During the journey the AT and RH were also recorded at each hour of the journey. The AT and RH were recorded using a wet- and dry-bulb thermometer (Branman, England). The RH was obtained by calculating the depression point from the AT and wet-bulb temperature values. The temperature-humidity index (THI), which is a measure of heat load, was recorded using an automatic meteorological digital calculator (Bruce \& Hall 2009).

\section{Birds and management}

Forty, apparently, healthy and three-and-half-month-old farmed ostrich chicks, belonging to the Red Neck breed and of both sexes served as subjects. The average weight of the birds was $27.7 \mathrm{~kg}$. The birds were obtained from a commercial farm located near Zaria $\left(11^{\circ} 10^{\prime} \mathrm{N}, 07^{\circ} 38^{\prime} \mathrm{E}\right)$ in the Northern Guinea Savannah zone of Nigeria. The chicks were kept on the farm for two weeks, during which they were accustomed to handling in a carol before transportation to two newly established farms in Raba $\left(10^{\circ} 19^{\prime} \mathrm{N}, 4^{\circ} 58^{\prime} \mathrm{E}\right)$, Nigeria. At the new farms, the chicks were kept in standard communal pens (Bertram 1992, Foggin 1992) of about one hectare of land, and each pen was surrounded by 6 -strand plain wire fence with droppers fixed at every $800 \mathrm{~mm}$. The main post was kept at $5 \mathrm{~m}$ apart. A standing roofed-structure, $3.5 \mathrm{~m}$ tall and with cement block wall ( $10 \mathrm{~m}$ long and $5 \mathrm{~m}$ wide) only at the northern side was provided as shelter and also for keeping feed and water troughs. The pens had runs of 1.5 to $4 \mathrm{~m}$ wide for adequate exercise and tall trees 
which served as shade during the hot hours of the day. Eight feeders and eight water troughs (Murray Goulburn, Australia) were provided for the chicks. The troughs were made of galvanized non-skid frame with stand and measured $480 \times 250 \mathrm{~mm}$ wide. Each trough had a capacity of 50 I of water and was kept clean daily. The chicks were fed ostrich growers' mash (Feed Master Ltd., Kaduna, Nigeria) with nutritive value of $2465 \mathrm{kcal} / \mathrm{kg}$ metabolized energy, $22 \%$ protein and $12 \%$ fibre. They were given access to water ad libitum in both the old and new farms.

\section{Experimental measurements}

The meteorological data and the behavioural events of the ostrich chicks were recorded 7 days before transportation, during transportation, three hours post-transportation, and subsequently for the next 7 days post-transportation. The behavioural events of standing, lying down, sleeping, pecking, urination/defecation (elimination), fear (measured as pen investigation, with the heads and tails of the chicks lowered to the ground), eating and drinking were recorded as earlier described (Wotton \& Hewitt 1999, Minka \& Ayo 2008) with little modification in timing. Briefly, the behavioural events of individual chicks were recorded visually and by the aid of a video camera. Observations on behavioural events were made during alternating $1 \mathrm{~h}$ period, with $1 \mathrm{~h}$ of observation and $1 \mathrm{~h}$ of pause, from 07:00 to 18:00 three times a week before and after transportation. The pause periods were alternated to insure the inclusion of every hour of the day. During the transportation, the behavioural events of individual chicks were recorded continuously and for the next $3 \mathrm{~h}$ post-transportation as described by Das et al. (2001) and Minka \& Ayo (2010). The behaviours were recorded by two observers inside the vehicle and each observer recorded on-going behavioural events of five chicks. The number of ostriches, frequency and time taken to perform each of the behavioural events of standing, lying, beak opening, wing fluffing, restlessness, sleeping, pecking, urination/defecation (elimination), fear (measured as pen investigation, with the heads and tails of the chicks lowered to the ground) and standing/lying orientation were recorded, whenever they were observed for each hour of the transportation period. The number of bouts or occurrence of each behaviour was recorded as the number of events per chick. Drinking behaviour was recorded as the total number of visits to the drinker and the time taken for each chick to drink water per visit within the recording period.

The live weights of the ostriches were recorded just before, immediately after, and on the 3rd and 6th day after transportation, using a Tanita veterinary scale, VT-900 (Accurate Scales Inc., Terre Hause, USA) with the platform fixed toward a depressed ground. The chicks were easily walked over it individually to minimize handling stress.

\section{Physical examination for traumatic injuries}

On transportation day and during handling and loading, each ostrich was examined physically and by palpation from the head to the toes as earlier described (Minka \& Ayo 2007b, 2008). The area of the body covered with feathers was examined by brushing the feathers with one hand against the direction of the feathers, which paved way for close examination of the underlying skin of the birds. Injured areas detected were immediately cleaned with cotton wool soaked with disinfectant, after which an adhesive plaster indicating the type, period and possible cause of the injury was pasted at the site. On arrival and immediately after unloading, similar physical examination was performed on the ostriches. 


\section{Vehicle design}

The vehicles used for the transportation were four modified Bedford vans (Made in England). The floor of the vehicles, which was secured of gaps and holes, were covered with chopped wood shavings with non-slippery rubber mats fixed on top. The windows were covered with grills that permitted the regulation of ventilation and provided with dark perforated curtain materials. Each vehicle was partitioned into 10 compartments with detachable and perforated plastic materials measuring $0.7 \mathrm{~m}$ high. Each compartment housed one ostrich chick comfortably, and with enough space for the chick to lie down. Although recommendations on stocking density for ostrich chicks during transportation are lacking (Wotton \& Hewitt 1999), in the present study the chicks where stocked at a density of $0.35 \mathrm{~m}^{2} / \mathrm{chick}$. Each partition was fixed in place after loading each ostrich into the vehicle. Similarly, during unloading the partitions were detached separately, starting from the rear end of the vehicle to the inside.

\section{Loading and transportation procedures}

The handling and loading of ostriches into the vehicles were done according to standard procedures, described by Sales \& Smith (1995) and Wotton \& Hewitt (1999). Transportation was done during the hot-dry period of March on each experimental day from 08:00. Four separate journeys were conducted. Each vehicle was loaded with 10 ostriches. The vehicles covered a distance of $305 \mathrm{~km}$ on an asphalt road. The average speed was $50 \mathrm{~km} / \mathrm{h}$. The driving conditions of the vehicles were similar. The journey lasted $6 \mathrm{~h}$. Food and water were withdrawn completely $6 \mathrm{~h}$ before and during the journey period. On arrival, the ostriches were immediately hooded out of the vehicles individually through a provided horizontal unloading bay and immediately through the weigh scale into pens, where the ostriches were fed the same ration given to them before the transportation. During the study period, the ostriches were humanely handled and transported as recommended by the Animal Welfare Order (MAFF 1988) and Farm Animal Welfare Council (FAWC 2003) and Animal Disease Control, Decree (1988) of the Federal Republic of Nigeria.

\section{Statistical analysis}

The mean and standard error of different behavioural events were calculated. Data were subjected to Student's $t$-test, and Pearson's correlation analysis was employed in calculating the relationships between the journey period, dry-bulb-temperature and behavioural events. Values of $P<0.05$ were considered significant.

\section{Results}

\section{Meteorological data}

The AT, $\mathrm{RH}$ and $\mathrm{THI}$ recorded during transportation are shown in Table 1. The AT value recorded at the farm before transportation ranged between 20.5 and $39^{\circ} \mathrm{C}$, while the $\mathrm{RH}$ values were $77-80 \%$. The mean AT, RH and THI were $32.5 \pm 2.2^{\circ} \mathrm{C}, 794 \pm 11 \%$ and $47 \pm 0.6^{\circ} \mathrm{C}$, respectively, and the values were not different $(P>0.05)$ from the mean post-transportation values of $31.9 \pm 0.7,81.5 \pm 15 \%$ and $45.4 \pm 1.1^{\circ} \mathrm{C}$, respectively for $\mathrm{AT}, \mathrm{RH}$ and $\mathrm{THI}$. 
Table 1

Thermal microclimatic environment inside the vehicle during six hours transportation period

\begin{tabular}{lccc}
\hline Hour of journey & Dry-bulb temperature, ${ }^{\circ} \mathrm{C}$ & Relative humidity, $\%$ & Heat stress index, ${ }^{\circ} \mathrm{C}$ \\
\hline Before transportation & 28.5 & 64 & 30.8 \\
1 & 30.7 & 72 & 37.4 \\
2 & 31.4 & 77 & 38.9 \\
3 & 32.7 & 80 & 47.0 \\
4 & 34.5 & 84 & 56.9 \\
5 & 38.6 & 87 & 81.8 \\
6 & 39.8 & 88 & 90.7 \\
Mean \pm SEM & $33.7 \pm 1.3$ & $78.9 \pm 3.2$ & $54.7 \pm 10.4$ \\
\hline
\end{tabular}

\section{Traumatic injuries}

Mild lacerations on the leg regions were sustained by $15 \pm 2.3 \%$ of the ostrich chicks during handling and loading. Thereafter, no injury was sustained throughout the journey and unloading periods.

\section{Behavioural events during transportation}

The behavioural events of the ostrich chicks during the transportation are shown in Table 2. Majority of the ostriches were restless, unstable, stood and eliminated frequently during the 1st and $2 n d h$ of the journey. Pecking, elimination of whitish colour of urine and faeces, beak opening and wing fluffing behaviours were manifested from the $3 \mathrm{rd}$ and 4 th $\mathrm{h}$ of the journeys. The percentage of chicks that exhibited the behaviours of beak opening $(66.7 \pm 21.2 \%)$, wing fluffing $(65.0 \pm 12.0 \%)$ and standing $(60.0 \pm 15.3 \%)$ during the journey were higher, when compared to those of other behavioural events.

Table 2

Effect of transportation on percent number of ostrich chicks that exhibited different behavioural activities per hour of the journey $(n=40)$

\begin{tabular}{|c|c|c|c|c|c|c|c|}
\hline \multirow[b]{2}{*}{ Behavioural activity } & \multicolumn{6}{|c|}{ Hour of the journey } & \multirow[b]{2}{*}{ Mean \pm SEM } \\
\hline & 1 & 2 & 3 & 4 & 5 & 6 & \\
\hline Standing & 100.0 & 100.0 & 50.0 & 60.0 & 50.0 & 0.0 & $60 \pm 15.3^{b}$ \\
\hline Lying down & 0.0 & 0.0 & 50.0 & 40.0 & 50.0 & 100.0 & $40 \pm 15.3^{\mathrm{a}}$ \\
\hline Sleeping & 0.0 & 0.0 & 0.0 & 0.0 & 40.0 & 80.0 & $20 \pm 14.9^{c}$ \\
\hline Elimination & 100.0 & 70.0 & 50.0 & 30.0 & 20.0 & 0.0 & $45 \pm 15.5^{c}$ \\
\hline Restlessness & 100.0 & 70.0 & 80.0 & 50.0 & 20.0 & 20.0 & $56.7 \pm 9.6^{c}$ \\
\hline Beak opening & 0.0 & 0.0 & 100.0 & 100.0 & 100.0 & 100.0 & $66.7 \pm 21.2^{b}$ \\
\hline Wing fluffing & 0.0 & 0.0 & 90.0 & 100.0 & 100.0 & 100.0 & $65 \pm 12.0^{b}$ \\
\hline Pecking & 0.0 & 0.0 & 0.0 & 60.0 & 100.0 & 100.0 & $43.3 \pm 21.7^{\mathrm{a}}$ \\
\hline
\end{tabular}

$a, b, c$ Values with different superscript alphabets along the same row are significantly different $(P<0.01)$.

The number of bouts for each behavioural events recorded during the journey is shown in Table 3. The most frequent behaviours exhibited during the first and second hours of the journeys were elimination and restlessness, followed by behaviours of beak opening, pecking and sleeping which were manifested during the third hour of the journeys. Overall mean, beak opening ( $5.9 \pm 1.5$ bouts), elimination ( $5.3 \pm 0.7$ bouts) and pecking ( $5.6 \pm 2.8$ bouts) were the most frequent behaviours exhibited by the ostriches during the journey periods. More time 
$(P<0.05)$ was spent exhibiting standing, lying, beak opening, pecking and restless behaviours during the journey periods (Table 4). At the last hour of the journey and immediately after, especially at the 4 th $h$ after the journey, the chicks appeared lethargic and fatigue.

Table 3

Number of bouts in behavioural activities per hour exhibited by ostriches during six hours road transportation $(n=40)$

\begin{tabular}{lccccccc}
\hline & \multicolumn{7}{c}{ Hour of the journey } \\
Behavioural activity & 1 & 2 & 3 & 4 & 5 & 6 & Mean \pm SEM \\
\hline Standing & 2.0 & 2.2 & 2.4 & 1.2 & 0.5 & 0.0 & $1.4 \pm 2.0^{\mathrm{a}}$ \\
Lying down & 0.0 & 0.0 & 2.4 & 1.2 & 0.5 & 0.3 & $0.7 \pm 0.7^{\mathrm{b}}$ \\
Sleeping & 0.0 & 0.0 & 0.0 & 0.0 & 1.4 & 4.5 & $1.0 \pm 3.8^{\mathrm{a}}$ \\
Elimination & 16.0 & 13.3 & 1.0 & 0.0 & 0.9 & 0.3 & $5.3 \pm 2.2^{\mathrm{c}}$ \\
Restlessness & 2.0 & 4.4 & 1.0 & 1.5 & 0.8 & 1.5 & $1.9 \pm 2.8^{\mathrm{a}}$ \\
Beak opening & 0.0 & 0.0 & 12.0 & 11.1 & 7.6 & 4.5 & $5.9 \pm 1.8^{\mathrm{c}}$ \\
Wing fluffing & 0.0 & 0.0 & 1.4 & 0.7 & 1.4 & 0.9 & $0.7 \pm 1.3^{\mathrm{b}}$ \\
Pecking & 0.0 & 0.0 & 0.0 & 4.4 & 10.8 & 18.2 & $5.6 \pm 2.8^{\mathrm{c}}$ \\
\hline
\end{tabular}

$a, b, c$ Values with different superscript alphabets along the same row are significantly different $(P<0.01)$.

Table 4

Time (min) spent on each behaviour per hour during six hours road transportation of ostrich chicks $(n=40)$

\begin{tabular}{|c|c|c|c|c|c|c|c|}
\hline \multirow[b]{2}{*}{ Behavioural activity } & \multicolumn{6}{|c|}{ Hour of the journey } & \multirow[b]{2}{*}{ Mean \pm SEM } \\
\hline & 1 & 2 & 3 & 4 & 5 & 6 & \\
\hline Standing & 60.0 & 60.0 & 20.0 & 10.0 & 15.0 & 0.0 & $27.0 \pm 11.8^{b}$ \\
\hline Lying down & 0.0 & 0.0 & 20.0 & 10.0 & 15.0 & 60.0 & $17.5 \pm 4.2^{\mathrm{a}}$ \\
\hline Sleeping & 0.0 & 0.0 & 0.0 & 0.0 & 0.5 & 1.0 & $0.3 \pm 0.2^{c}$ \\
\hline Elimination & 0.5 & 0.3 & 0.5 & 0.0 & 0.3 & 0.0 & $0.3 \pm 0.1^{c}$ \\
\hline Restlessness & 45.0 & 30.0 & 20.0 & 0.0 & 9.4 & 5.0 & $18.2 \pm 1.0^{\mathrm{a}}$ \\
\hline Beak opening & 0.0 & 0.0 & 5.0 & 20.0 & 30.0 & 30.0 & $14.2 \pm 3.0^{\mathrm{a}}$ \\
\hline Wing fluffing & 0.0 & 0.0 & 5.0 & 10.0 & 15.0 & 15.0 & $7.5 \pm 2.1^{d}$ \\
\hline Pecking & 0.0 & 0.0 & 0.0 & 0.3 & 0.3 & 0.3 & $0.15 \pm 0.0^{c}$ \\
\hline
\end{tabular}

$a, b, c, d$ Mean values with different superscript alphabets along the same row are significantly different $(P<0.01)$.

Table 5

Relationships between the hour of the journey, temperature humidity index, number of chicks, time spent and frequency of each behavioural activity during the journey $(n=40)$

\begin{tabular}{|c|c|c|c|c|c|c|c|c|}
\hline \multirow[b]{2}{*}{$\begin{array}{l}\text { Correlated } \\
\text { parameters }\end{array}$} & \multicolumn{8}{|c|}{ Correlation coefficients of behavioural activities } \\
\hline & Standing & $\begin{array}{l}\text { Lying } \\
\text { down }\end{array}$ & Sleeping & Elimination & Restlessness & $\begin{array}{c}\text { Beak } \\
\text { opening }\end{array}$ & $\begin{array}{l}\text { Wing } \\
\text { fluffing }\end{array}$ & Pecking \\
\hline $\begin{array}{l}\text { Hour of journey } \\
\text { and time spent }\end{array}$ & $-0.914^{* * *}$ & $0.803^{* * *}$ & $0.823^{* * *}$ & $-0.710^{* *}$ & $-0.886^{* * *}$ & $0.954^{* * *}$ & $0.969^{* * *}$ & $0.878^{* * *}$ \\
\hline $\begin{array}{l}\text { Hour of journey and } \\
\text { number of bouts }\end{array}$ & $-0.892^{* * *}$ & $0.109^{\text {ns }}$ & $0.784^{* *}$ & $-0.849^{* * *}$ & $-0.513^{*}$ & $0.448^{\text {ns }}$ & $0.673^{* *}$ & $0.939^{* * *}$ \\
\hline $\begin{array}{l}\text { Hour of journey } \\
\text { and percent number } \\
\text { of chicks }\end{array}$ & $-0.914^{* * *}$ & $0.914^{* * *}$ & $0.831^{* * *}$ & $-0.989^{* * *}$ & $-0.949^{* * *}$ & $0.828^{* * *}$ & $0.857^{* * *}$ & $0.926^{* * *}$ \\
\hline $\begin{array}{l}\text { THI and } \\
\text { time spent }\end{array}$ & $-0.935^{* * *}$ & $0.704^{* * *}$ & $0.679^{* *}$ & -0.464 & -0.746 & $0.903^{* * *}$ & $0.936^{* * *}$ & $0.841^{* * *}$ \\
\hline $\begin{array}{l}\text { THI and number } \\
\text { of bouts }\end{array}$ & $-0.778^{* *}$ & $0.282^{\mathrm{ns}}$ & $0.631^{* *}$ & $-0.926^{* * *}$ & $0.517^{*}$ & $0.614^{* *}$ & $0.761^{* *}$ & $0.854^{* * *}$ \\
\hline $\begin{array}{l}\text { THI and percent } \\
\text { number of chicks }\end{array}$ & $-0.824^{* * *}$ & $0.712^{* *}$ & $0.689^{* *}$ & $-0.674^{* *}$ & $-0.567^{*}$ & $0.923^{* * *}$ & $0.847^{* * *}$ & $0.902^{* * *}$ \\
\hline
\end{tabular}

${ }^{n s}$ non-significant difference, $P>0.05,{ }^{*} P<0.05,{ }^{* *} P<0.01,{ }^{* * *} P<0.001$ 
The number of chicks, frequency and time spent on each behavioural event of sleeping, beak opening, wing fluffing and pecking during transportation were positively and significantly correlated with the THI and hour of the journey. The frequency of lying behaviours was positively, but not significantly correlated with the THI and hour of the journey. Elimination, standing and restlessness behaviours were negatively and significantly correlated (Table 5).

\section{Live weight}

Immediately after the journey the ostrich chicks loss $6.5 \pm 1.4 \%$ of their initial live weight. The initial live weights of the ostriches were restored after 7 days of post-transportation.

\section{Behavioural activities during pre- and post-transportation period}

The behavioural events of the ostrich chicks 7 days before transportation showed that the chicks spent more time pecking $(60 \pm 1.2 \%)$, lying down ( $35 \pm 0.6)$ and standing $(5.0 \pm 1.5 \%)$ out of $12 \mathrm{~h}$ active day. Fear behaviour manifested as pen investigation was not recorded before transportation period. However, during the first three hours of post-transportation period all the chicks spent the first two hours standing and investigated the new pens with their heads and tails lowered to the ground, and none of the chicks ate or drank water during the 1sth of post-transportation. The behaviours of the chicks for 7 days post-transportation period showed that each chick per day spent $40.0 \pm 3.2 \%$ pecking, $10.7 \pm 1.7 \%$ standing idle and $40.2 \pm 5.2 \%$ investigating the pen. The results obtained post-transportation period showed that the ostriches pecked less, but stood longer per $12 \mathrm{~h}$ active day compared to the results recorded during pre-transportation period.

\section{Discussion}

The thermal environmental data recorded during the transportation were characterized by high AT, RH, THI and prolonged solar radiation, typical of the hot-dry period in the Northern Guinea Savannah zone of Nigeria. Although ostriches are known to withstand high ambient temperature up to $40^{\circ} \mathrm{C}$, several studies have shown that transportation of chicks under incremental weather conditions may result in severe stress (Reiner et al. 1996, Wotton \& Hewitt 1999). The AT and RH values recorded during the transportation in this study were considerably higher than the $\mathrm{AT}$ and $\mathrm{RH}$ values of $31.07^{\circ} \mathrm{C}$ and $75-85 \%$, respectively recorded by Piccione et al. (2005) during transportation of ostrich chicks, which resulted in severe stress and high mortality. In both studies the AT values were higher than the recommended thermo neutral range of $20-22^{\circ} \mathrm{C}$ (Alldredge 1993). The result suggests that the meteorological conditions were unfavourable to the ostriches, particularly during the hot hours of the day when the THI value attained its peak. At this period of the day, heat stress was apparent, and posed a significant threat to the thermoregulatory mechanisms and general welfare of the birds. Payne (1993) showed that ostriches transported at AT value of $18^{\circ} \mathrm{C}$ and $\mathrm{RH}$ value of $89 \%$ suffered stress, mainly due to novelty of environment and loading procedures. Although several studies conducted during the hot-dry conditions in the zone have shown consistency in high ambient temperature and relative humidity during transportation of 
livestock including poultry, the effects of thermal load (combined effects of AT and RH) on livestock in these studies were not quantified.

Traumatic injuries encountered in ostriches during road transportation have been a major problem in the ostrich industry, causing considerable economic losses in terms of mortality, poor meat and skin quality (Mitchell et al. 1996, Wotton \& Hewitt 1999, Meyer et al. 2003, Minka \& Ayo 2008). In the present study, the provision of individual and conducive compartment for each ostrich chick in the vehicle eliminated trampling and smothering of the birds, which often results in injuries during road transportation of ostriches in groups using vehicles that were not partitioned into individual compartments (Ayo \& Minka 2004, Minka \& Ayo 2008). The vehicle design used in the present study was better than crating or group loading of ostriches which is often practiced today and known to be associated with incidence of injuries and death during transportation (Wotton \& Hewitt 1999, Crowther et al. 2003, Minka \& Ayo 2008).

In spite of the advantages of the present vehicle design in mitigating transportation injuries, other transportation stress factors, such as vehicle novelty and instability, vibration, motion and noise from the engine, and the adverse effects of weather conditions were apparently involved in exerting road transport stress and inducing stressful behavioural responses such as prolonged-standing, hyperventilation, pecking and wing fluffing.

The ostriches manifested physical signs of stress starting from the 3rd hour of the journey by fluffing out their wings and hyperventilation, evidenced by beak opening in order to enhance the exchange of gases for cooling the body. The behavioural activity were, apparently, due to the need for the chicks to increase heat dissipation, induced by water deprivation, heat generated by the chicks themselves and high THI recorded inside the vehicle during the journey period. Anthony (1992) and Piccione et al. (2005) showed that at $30.4^{\circ} \mathrm{C}$ and $31.07^{\circ} \mathrm{C}$, which were lower than the value of $39.8 \pm 0.3^{\circ} \mathrm{C}$ recorded in the present study, birds begin to pant and expend a lot of energy during panting. The findings were similar to the observations made by Harris (1996), Wotton \& Hewitt (1999) that hot-humid environment, often associated with fluctuations in high $\mathrm{AT}$ and $\mathrm{RH}$, poor ventilation and water deprivation during transportation are harmful to ostrich chicks.

The elimination of whitish colour of urine and faeces by the ostriches from the 3rd and 5 th $h$ of the journey suggested that the birds were dehydrated (Wotton \& Hewitt 1999). This may be as a result of feed and water deprivation, increase respiration due to high THI, and high frequency of defecation and urination. The increase in defecation and urination, which occurred right from the onset of the journey, was apparently, as a result of increased excitation of the nervous system of the chicks due to handling and novelty stress. Frequent elimination and hyperventilation have been reported to cause significant water loss in adult ostriches (Aganga et al. 2003). The manifestation of intense pecking behaviour at the last hours of the journey suggested that the chicks were metabolically stressed, hungry and thirsty. The results supported the previous findings of Foggin (1992) who showed that stressed and hungry ostriches during road transportation pick up a variety of harmful materials, apparently due to increase in their pecking behaviour.

The disrupted short duration of sleep at the last hour of the journey further confirmed the fact that the ostriches were stressed and fatigued during the journey. This finding showed that although the chicks needed rest, the multiple stressors acting on them during the journey 
did not allow them to have adequate rest and sleep. Similar disrupted sleep was shown to be an abnormal behaviour in ostriches of all ages (Samson 1997). The increase in the percent frequency and time spent on behavioural events $3 \mathrm{~h}$ into the journey, with the exception of standing and elimination behaviours, suggested that the birds were discomforted as the journey progressed. Therefore, they changed their behavioural frequencies and spent more time on favourable and adaptational behaviours like beak opening and wing fluffing, which enhanced the thermoregulation in the birds. The standing and lying orientations of the birds observed parallel to the direction of movement of the vehicle during the journey were similar to the results obtained in transported goats (Das et al. 2001). The factors responsible for such orientation in animals during transportation require further investigation.

The positive correlations obtained between the hour of the journey, THI and the stressful behavioural activities of beak opening, wing fluffing, pecking, sleeping and lying down showed that road transportation induced stressful behavioural events and the level of stress rose as the THI and hour of the journey increased. Thus, the shorter the journey the less adverse effect it may have on the birds; and the higher the THI inside the vehicle during the journey, the more stressful the behavioural activities of the birds. This finding is in agreement with the result obtained in transported cattle by road during the hot-dry season (Minka \& Ayo 2007a) that higher dry-bulb temperatures and duration of journey increase the level of stress manifestations. The significant increase in the correlation coefficients for lying, sleeping, pecking and wing fluffing behaviours in the ostrich chicks as the THI and hour of the journey rose was an evidence that the birds were fatigued and their excitability decreased markedly as the journey time increased. These behavioural events were induced as a result of physiological responses of the birds to thermal micro-environmental conditions inside the vehicle. The negative correlation obtained between the hours of the journey, THI and behaviours of standing, elimination and restlessness may be a psychological response due to handling, loading and novelty of transportation conditions, rather than the effect of THI. The results of the present study showed, for the first time, the relationships between the THI, hour of the journey and behavioural activities of ostrich chicks, transported by road during the hot-dry conditions.

The observed frequent elimination and keen investigation of the new pen after unloading demonstrated an increase in excitability and fear response in the chicks. Such behaviour by the chicks was reported to be an indication of fear or submissiveness in ostrich chicks (Bertram 1992). The refusal of the chicks to eat or drink during the first hour of post-transportation, in spite of adequate feed and water provision, suggested that the unloading and introduction of the ostriches to new environment triggered a new level of stress and excitation of the nervous system. A long stimulatory effect on the hypothalamo-pituitary-adrenal axis and sympathetic nervous system as a result of stress was reported to release substances that inhibit ingestive behaviour and series of metabolic activities (Mitchell et al. 1996, Richardson 2005).

The loss in live weight of the chicks post-transportation may be attributed to feed deprivation, increased elimination of the gut content and urine, and evaporation of body water through the increased hyperventilation recorded during the journey. The restoration of the initial live weight at the 6th day post-transportation, in spite of adequate feed and water provision, was an indication that road transportation actually caused the decrease in 
live weight, apart from the effects of feed deprivation and elimination of the gut content. The $6 \%$ loss in live weight recorded in this study was similar to the value of $6.8 \%$ weight loss reported by Piccione et al. (2005) during $12 \mathrm{~h}$ of transportation of ostrich chicks, but higher than the value of $4.5 \%$ recorded in transported ostrich chicks by Sales \& Smith (1995). The restoration of the initial live weight of the chicks 7 days post-transportation was longer than 2 to 3 days restoration period recorded by Piccione et al. (2005). The present result indicated that transportation of ostrich chicks for $6 \mathrm{~h}$ during the hot-dry season had a serious consequential effect on their live weights, thus, may decrease their market value. For the birds to regain their initial live weights they need to be kept and fed for at least 7 days after transportation and this may have economic implications for the farmer.

The pre-transportation behavioural events were not completely restored for 7 days posttransportation, which suggested that the stresses imposed on the birds during the journey and their introduction to a new environment exerted prolonged stress. This finding disagreed with earlier observations made in poultry (Freeman 1984, Minka \& Ayo 2007b) transported by road, that pre-transportation values were restored 3 days post- transportation. The times spent exhibiting standing, eating and drinking behaviours pre- and post-transportation were different from those obtained by Milton et al. (1993) and Aganga et al. (2003), who showed that ostriches out of $12 \mathrm{~h}$ active day spent $20.4 \%$ lying down, $5.5 \%$ standing, $12 \%$ eating and $1.1 \%$ drinking water. Williams et al. (1993) showed that wild adult and juvenile ostriches in Namib Desert spent nearly $7.5 \mathrm{~h}$ walking and $11.5 \mathrm{~h}$ roosting per $24 \mathrm{~h}$. The frequency of pecking behaviour, which included pecking of the food, ground and air, obtained in the present study was lower than the value of $89 \%$ pecking activity/ostrich/day recorded in captive ostrich chicks (Milton et al. 1993). These variations in behaviours may be due to different management techniques and ages of the birds. The fear behaviour manifested by the ostriches in the pen for 7 days post-transportation, on hearing of noise, viewing moving objects or following introduction of the ostrich attendant demonstrated that the unloading and introduction to a new environment and attendant increased the excitability of the nervous system. Besides, the ostrich chicks may be dichromate and, therefore, more sensitive to seeing sudden movement of objects and high contrast of light or dark. Such a reaction to various movements by dichromate animals is known to activate the fear centre (amygdala) of the brain (LeDoux 1996). In addition, ostriches are known to become stressed by a change in attendant and routine (Wotton \& Hewitt 1999).

In general, the result suggested that $\mathrm{THI}$ of $33-40^{\circ} \mathrm{C}$ constituted moderate risk, while $\mathrm{THI}$ of 47 and above may result in severe stressful behaviours, and this classification may be used as recommended ranges and limits of thermal load values in transported ostrich chicks. This requires further investigation.

It is concluded that road transportation of the ostrich chicks during the hot-dry conditions and the introduction of the birds into a new environment induced transit stressful behavioural events, and live weight losses which lasted 7 days after the transportation. The provision of individual compartments for each ostrich inside the vehicle during the journey mitigated the incidence of traumatic injuries. 


\section{Acknowledgements}

The authors are grateful to Mr. J. N Bawa, the Chairman Vagosh Farm Ltd., Raba for supporting this work financially.

\section{References}

Aganga AA, Aganga AO, Omphile UJ (2003) Ostrich feeding and nutrition. Pak J Nutr 2, 60-67

Animal Diseases Control Decree (1988) Federal Republic of Nigeria Official Gazettes. The Federal Government Press, Lagos, Nigeria 75, 477-491

Anthony JS (1992) The Tropical Agriculturist. Macmillan Press, New York, USA

Alldredge Jr. BE (1993) Chick rearing. In: Bryden DI (ed.) Chicken Odyssey. University of Sydney Post-graduate Committee in Veterinary Science, Proc. No. 217 University of Sydney, 145-146

Ayo JO, Minka NS (2004) Effect of six-hour road transportation on some physiological parameters in ostriches. Proc. 29th Ann Conf Nig Soc Anim Prod, Sokoto, Nigeria 29, 58-61

Ayo JO, Oladele SB, Fayomi A (2002) Behavioural reactions of cattle to stress situations: A review. J Agri Technol $8,15-20$

Bertram BCR (1992) The Ostrich Communal Nesting System. Princeton University Press, Princeton, NJ, USA

Bruce T, Hall T (2009) National Weather Service Office, EIP, Pso, Texas, USA

Brown C (1997) Ostrich Investigation. Poultry Press, California, CA, USA

Cooper RG, Horbanczuk JO (2000) Anatomical and physiological characteristics of ostrich (Struthio camelus var. domesticus) meat determine its nutritional importance for man. Anim Sci J 73, 167-173

Crowther C, Davies R, Glass W (2003) The effect of night transportation on the heart rate and skin temperature of ostriches during real transportation. Meat Sci 64, 365-370

Das KS, Srivastava BB, Das N (2001) Standing orientation and behaviour of goats during short-haul road transportation. Small Rum Res 41, 91-94

Farm Animal Welfare Council (FAWC) (2003) Farm animal at slaughter or killing. Part 1. Red meat animals. Defra Publication, Admail, London, UK

Foggin CM (1992) Veterinary problems of ostriches. In: Hallam MG (ed.) The Topaz Introduction to Practical Ostrich Farming. The Ostrich Producers' Association, Harare, Zimbabwe, 62-95

Freeman BM (1984) Transportation of poultry. World Poult Sci J 40, 19-30

Harris TC (1996) AATA Manual for the transport of live animals by road. Animal Transportation Association, Redhill, UK

LeDoux J (1996) The Emotional Brain. The Mysterious Underpinnings of Emotional Life. Simon \& Schuster, New York, NY, USA

MAFF (1998) The Welfare of Animals (Transport) Order 1997. The Stationery Office, London, UK

Meyer A, Cloete SWP, Brown CR (2003) The influence of separate-sex rearing on ostrich behaviour and skin damage. S Afr J Anim Sci 33, 95-104

Milton S, Dean WRJ, Linton A (1993) Consumption of termites by captive ostrich chicks. S Afr J Wildl Res 23, $58-60$

Minka NS (2003) Evaluation of the performance of ostrich chicks to juvenile age in Northern Nigeria. Trop J Anim Sci 6, 69-73

Minka NS, Ayo JO (2007a) Effects of loading behaviour and road transport stress on traumatic injuries in cattle transported by road during the hot-dry season. Livest Sci 107, 91-95

Minka NS, Ayo JO (2007b) Haematology and behaviour of pullets transported by road and administered with ascorbic acid during the hot-dry season. Res Vet Sci 85, 389-393 
Minka NS, Ayo JO (2007c) Road transportation effect on rectal temperature, respiration and heart rates of ostrich (Struthio camelus) chicks. Vet Arhiv 77, 39-46

Minka NS, Ayo JO (2008) Assessment of the stresses imposed on adult ostriches (Struthio camelus) during handling, loading, transportation and unloading. Vet Rec 162, 846-851

Minka NS, Ayo JO (2010) Behavioural and rectal temperature responses of Black Harco pullets administered vitamins $C$ and $E$ and transported by road during the hot-dry season. J Vet Behav Clin Appl Res 5, 134-144

Mitchell MA, Kettlewell PJ, Sandercock R, Spackman DA (1996) Physiological stress in ostriches during road transportation. In: Deeming DC (eds.) Improving our understanding of ratites in farming environment. An international conference held at Dalton-Ellis Hall, University of Manchester, England, 27th-29th March 1996. Proceedings. Ratite Conference, Branbury/Oxfordshire, UK, 79-80

Payne $H$ (1993) Welfare of ostriches and other ratites during transport. State Vet J 3, 8-12

Piccione G, Costa A, Giudice E, Caola G (2005) Preliminary investigation into thermal stress during diurnal road transportation of young ostriches (Struthio Camelus). Arch Tierz 48, 194-200

Reiner G, Seitz K, Dzapo V (1996) A survey of farming environment and ostrich behaviour in Germay. In: Deeming DC (ed.) Improving our understanding of ratites in a farming environment. An international conference held at Dalton-Ellis Hall, University of Manchester, England, 27th-29th March 1996. Proc. Ratite Conference, Branbury/Oxfordshire, UK, 23-24

Richardson C (2005) Lowering Stress in Transported Goats. Ontario Ministry of Agriculture, Food and Rural Affairs. http://www.omafra.gov.on.ca/english/livestock/goat/facts/05-029.htm [last accessed 23.11.2011]

Sales J, Smith WA (1995) Incubation and Management. In: Smith WA (ed.) Practical Guide for Ostrich Management and Ostrich Products. Alltech Inc./Stellenbosch University Printers, South Africa, 3-7

Samson J (1997) Prevalent diseases of ostrich chicks farmed in Canada. Can Vet J 38, 425-428

Williams JB, Siegfried WR, Milton SJ, Adams NJ, Dean WRJ, du Plessis MA, Jackson S (1993) Field metabolism, water requirements, and foraging behaviour of wild ostriches in the Namib. Ecology 74, 390-404

Warriss PD, Kestin SC, Brown SN, Knowles TG, Wilkins LJ, Edwards JE, Austin SD, Nicol CJ (1993) The depletion of glycogen stress and indices of dehydration in transported broilers. Br Vet J 149, 391-398

Wotton SB, Hewitt L (1999) Transportation of ostriches - a review. Vet Rec 145, 725-731

Received 17 April 2011, accepted 23 August 2011.

Corresponding author:

Ndazo Salka Minka

email: mnsalka@yahoo.com

College of Agriculture and Animal Science, Division of Agricultural Colleges, P.M.B. 2134, Ahmadu Bello University, Mando - Kaduna, Nigeria 